\title{
Making nanosized CHA zeolite with controlled Al distribution for optimizing MTO performance
}

\author{
Eva M. Gallego, ${ }^{+}$Chengeng Li, ${ }^{+}$Cecilia Paris, Nuria Martín, Joaquín Martínez-Triguero, Mercedes \\ Boronat, Manuel Moliner, ${ }^{*}$ Avelino Corma*
}

\begin{abstract}
By theoretical calculations and a rational synthesis methodology, it has been possible to prepare nanocrystalline $(60-80$ $\mathrm{nm}$ ) chabazite with an optimized framework Al distribution that have a positive impact on its catalytic properties. This is exemplified for the methanol to olefins (MTO) process. The nanosized material with the predicted Al distribution maximizes the formation of the required MTO hydrocarbon pool intermediates, while better precluding excessive diffusion pathways that favor the rapid catalyst deactivation by coke formation.
\end{abstract}

The methanol to olefins (MTO) process allows the efficient generation of light olefins, such as ethylene or propylene, which are considered platform molecules to obtain several main compounds for the petrochemical industry. ${ }^{[1]}$ Small pore zeolites containing large cavities within their structure have been recognized as active and highly stable catalysts for the MTO process. ${ }^{[2]}$ The presence of the large cavities favors the formation and stabilization of the aromatic polymethylbenzene intermediates involved in the accepted "hydrocarbon pool" (HP) mechanism, ${ }^{[3]}$ while the small pores allow the diffusion of the linear light olefins, particularly ethylene and propylene, that are generated by successive methylation and cracking of the HP intermediates (see Figure 1). ${ }^{[4]}$ Nevertheless, these light olefins may further react yielding longer chain hydrocarbons, or participate in the aging of the aromatic HP intermediates into other polyaromatic species, like naphthalenes or phenanthrenes, that hinder the diffusion of products and finally block the cavities, leading to catalyst deactivation. $\left.{ }^{4 b}, 5\right]$

Up to now, the silicoaluminophosphate (SAPO) form of the $\mathrm{CHA}$ structure, named SAPO- $34,{ }^{[6]}$ is the preferred catalyst for the MTO process, ${ }^{[7]}$ because it exhibits a low tendency to deactivate by excessive formation of bulky aromatic products, especially when tested at moderate-high reaction temperatures (i.e. 450 $\left.500^{\circ} \mathrm{C}\right) .{ }^{[4 a]}$ However, the aluminosilicate counterpart, SSZ-13, presents a higher intrinsic activity and a lower optimum reaction temperature (i.e. $350-375^{\circ} \mathrm{C}$ ), ${ }^{[5 \mathrm{~b}]}$ which makes this zeolite a promising alternative to SAPO- 34 as catalyst for the MTO process. In order to enhance the catalytic performance of the aluminosilicate SSZ-13, particularly its stability against deactivation, many recent research efforts have focused on

\footnotetext{
E. M. Gallego,+ C. Li,+ Dr. C.Paris, Dr. N. Martín, Dr. J. MartínezTriguero, Dr. M. Boronat, Dr. M. Moliner, ${ }^{*}$ Prof. A. Corma* Instituto de Tecnología Química, Universitat Politècnica de València-Consejo Superior de Investigaciones Científicas, Avenida de los Naranjos s/n, 46022 València, Spain E-mail: mmoliner@itq.upv.es, acorma@itq.upv.es

${ }^{[+]}$These authors contributed equally to this work.
}

Supporting information for this article is given via a link at the end of the document decreasing the diffusion pathways of reactants and products within the SSZ-13 particles, including the preparation of nanosized crystals, ${ }^{[8]}$ or with high intra-crystalline mesoporosity. ${ }^{[9]}$ It is important to note that all these synthesis methodologies require the presence of sodium cations in the synthesis media.

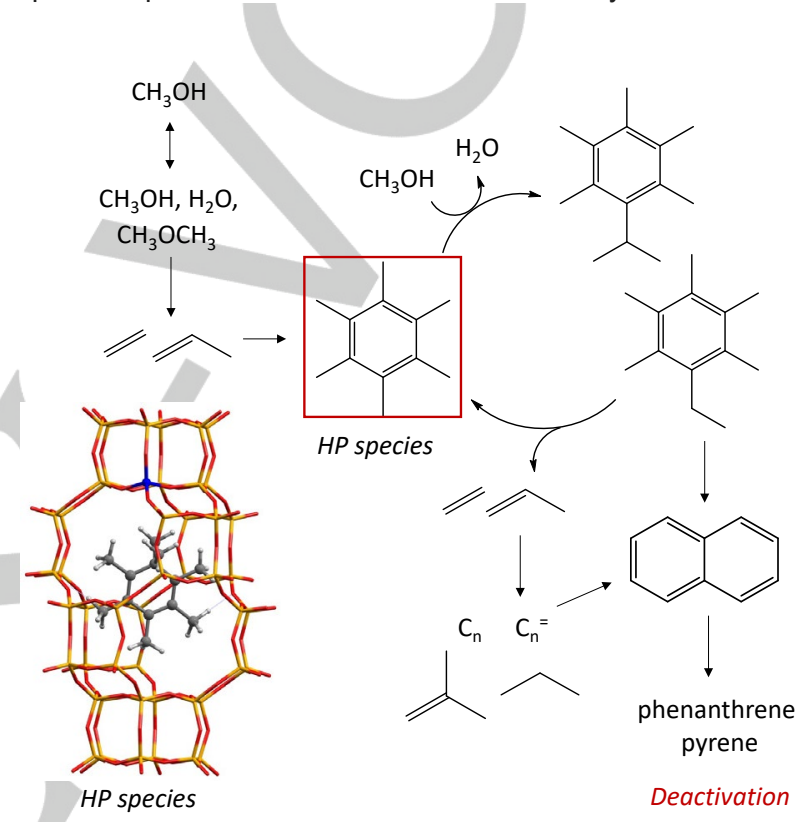

Figure 1. Proposed mechanism for the MTO reaction, showing the hydrocarbon pool (HP) species within the CHA cavity, and for catalyst deactivation by formation of polyaromatics.

A different factor that needs to be considered in relation to catalyst performance is the amount and distribution of Brønsted acid sites within the zeolite framework. According to the HP mechanism, each cavity in the $\mathrm{CHA}$ structure can only host one aromatic polymethylbenzene HP species under working conditions, compensated by one framework $\mathrm{Al}$ atom (see Figure 1). The synthesis methodology followed to prepare the $\mathrm{CHA}$ zeolite could have an impact on the Al distribution in the zeolite framework. In this sense, it has been recently described that the presence of $\mathrm{Na}^{+}$cations in the synthesis gel plays a fundamental role on the final Al distribution within the crystallized SSZ-13 zeolites. ${ }^{[10]}$ Indeed, for a given Si/Al of 15, the amount of paired $\mathrm{Al}$ atoms, which can be defined as $\mathrm{Al}$ atoms in close proximity separated by either one or two $\mathrm{Si}$ atoms $\left[\mathrm{Al}-\mathrm{O}(-\mathrm{Si}-\mathrm{O})_{\mathrm{x}}-\mathrm{Al} ; \mathrm{x}=1,2\right]$, increases when increasing the sodium content. ${ }^{[10 a]}$ The presence of sodium cations in the synthesis gel forces up to $10-20 \%$ of the tetrahedrally coordinated Al species in SSZ-13 to be placed close to other $\mathrm{Al}$ in the same $\mathrm{CHA}$ cavity, resulting in a significant increase in the number of cavities that do not contain Al. ${ }^{[10 a]}$ Considering that the acid-mediated MTO reaction mechanism preferentially works through the permanent formation of bulky 
aromatic intermediate species within the Al-containing $\mathrm{CHA}$ cavities (see Figure 1), it could envisioned that making more uniform the $\mathrm{Al}$ distribution along the $\mathrm{CHA}$ cavities, i.e. directing towards one Al per cavity, particularly within nanosized crystals, the catalytic performance and lifetime of the aluminosilicate SSZ13 could be maximized.

Herein, we will present the first synthesis descriptions of sodium-free nanocrystalline SSZ-13 materials with average crystal sizes in the nanoscale values $(\sim 60-80 \mathrm{~nm})$ with controlled Si/Al molar ratios ( 15 and 25$)$, by combining the use of precrystallized FAU zeolites as $\mathrm{Si}$ and $\mathrm{Al}$ sources with $\mathrm{N}, \mathrm{N}, \mathrm{N}$,trimethyladamantammonium $\left(\mathrm{TMAda}^{+}\right.$) as OSDA. The Na-free nanocrystalline SSZ-13 zeolites perform as excellent catalysts for the MTO reaction and, particularly, the Na-free nanosized SSZ13 with a Si/Al molar ratio of $\sim 15$, shows, at least, a 5- and 2.5fold increase in catalyst life compared to classical SSZ-13 and other nanosized SSZ-13 materials reported in the literature, respectively. The precise effect of $\mathrm{Na}^{+}$cations on the Aldistribution within the $\mathrm{CHA}$-based catalysts has been theoretically proven. The achieved results demonstrate that the combination of the nanocrystalline size with an optimized Al distribution within the SSZ-13 zeolite, allows a significant enhancement of its catalytic performance for the MTO reaction.

Table 1. Synthesis precursors and theoretical gel molar ratios for the different CHA-related zeolites.

\begin{tabular}{ccccc}
\hline Sample & Si source / Al source & $\mathrm{Si} / \mathrm{Al}$ & $\mathrm{NaOH} / \mathrm{Si}$ & OSDA \\
\hline CHA_1 & $\mathrm{SiO}_{2} / \mathrm{Al}(\mathrm{OH})_{3}$ & 15 & 0.0 & TMAda \\
CHA_2 & $\mathrm{SiO}_{2} / \mathrm{Al}(\mathrm{OH})_{3}$ & 25 & 0.0 & TMAda \\
CHA_3 & $\mathrm{FAU}(\mathrm{CBV720})$ & 14 & 0.0 & TMAda \\
CHA_4 & $\mathrm{FAU}(\mathrm{CBV760)}$ & 26 & 0.0 & TMAda \\
CHA_5 & $\mathrm{SiO}_{2} / \mathrm{Al}(\mathrm{OH})_{3}$ & 15 & 0.2 & TMAda \\
CHA_6 & $\mathrm{SiO}_{2} / \mathrm{Al}(\mathrm{OH})_{3}$ & 15 & 0.4 & $\begin{array}{c}\text { TMAda } \\
\text { CHA_7 }\end{array}$ \\
$\mathrm{SiO}_{2} / \mathrm{Al}(\mathrm{OH})_{3}$ & 15 & 0.2 & $\begin{array}{c}\text { TMAda+ } \\
\text { CTMA }\end{array}$ \\
\hline
\end{tabular}

As it has been stated above, all the nanocrystalline and/or mesoporous SSZ-13 materials that have been tested for the MTO reaction in the literature, have required the presence of $\mathrm{Na}$ in their synthesis procedures. ${ }^{[8-9]}$ Thus, considering that the presence of sodium in the synthesis media precludes the complete isolation of framework Al species per CHA cavity, ${ }^{[10 a]}$ the MTO catalytic activity observed for the nanosized and/or mesoporous SSZ-13 materials reported in the literature, can be, at least partially, masked by a lower amount of Al-containing $\mathrm{CHA}$ cavities available to undergo the MTO reaction for the given Si/AI molar ratios. In this sense, to evaluate the pure crystal size effect on MTO, we have first proposed the Na-free synthesis of the SSZ-13 zeolite with different crystal sizes, micron- and nano-sized, at two given Si/Al molar ratios ( 15 and 25$)$.

The synthesis of the micron-sized Na-free SSZ-13 materials has been previously described in the literature using TMAda as OSDA. ${ }^{[10 a]}$ Following the reported synthesis methodology, two different $\mathrm{Na}$-free micron-sized $\mathrm{CH}$ A materials have been prepared with Si/Al ratios of $\sim 15$ and $\sim 25$ (see CHA_1 and CHA_2, respectively, in Table 1 and synthesis details in the $\mathrm{SI}$ ). The achieved solids show the crystalline structure of CHA (see PXRD patterns of CHA_1 and CHA_2 in Figure S1), and their Si/Al molar ratios are analogous to those introduced initially in the gels (17.4 and 26.7 for CHA-1 and CHA-2, respectively, see Table 2). As expected, these $\mathrm{Na}$-free $\mathrm{CHA}$ samples show micron-sized crystals ( $1 \mu \mathrm{m}$, see CHA_1 and CHA_2 in Figure 2).

Table 2. Physico-chemical properties of the $\mathrm{CHA}$-related materials in their acid form

\begin{tabular}{ccccccc}
\hline Sample & Si/Al & $\begin{array}{c}\text { Crystal } \\
\text { size }(\mu \mathrm{m})\end{array}$ & $\begin{array}{c}\text { BET } \\
\left(\mathrm{m}^{2} / \mathrm{g}\right)\end{array}$ & $\begin{array}{c}\mathrm{S}_{\text {micro }} \\
\left(\mathrm{m}^{2} / \mathrm{g}\right)\end{array}$ & $\mathrm{S}_{\text {ext }}\left(\mathrm{m}^{2} / \mathrm{g}\right)$ & $\begin{array}{c}\mathrm{V}_{\text {miccro }} \\
\left(\mathrm{cm}^{3} / \mathrm{g}\right)\end{array}$ \\
\hline CHA_1 & 17.4 & $0.80-1.00$ & 472 & 448 & 24 & 0.26 \\
CHA_2 & 26.7 & $0.70-1.00$ & 596 & 586 & 10 & 0.28 \\
CHA_3 & 14.2 & $0.05-0.07$ & 577 & 495 & 82 & 0.25 \\
CHA_4 & 24.1 & $0.07-0.09$ & 630 & 480 & 76 & 0.25 \\
CHA_5 & 14.9 & $1.00-1.50$ & 520 & 517 & 3 & 0.25 \\
CHA_6 & 8.5 & $0.02-0.03$ & 630 & 570 & 60 & 0.26 \\
CHA_7 & 17.0 & $0.05-0.20$ & 530 & 401 & 129 & 0.20 \\
\hline
\end{tabular}
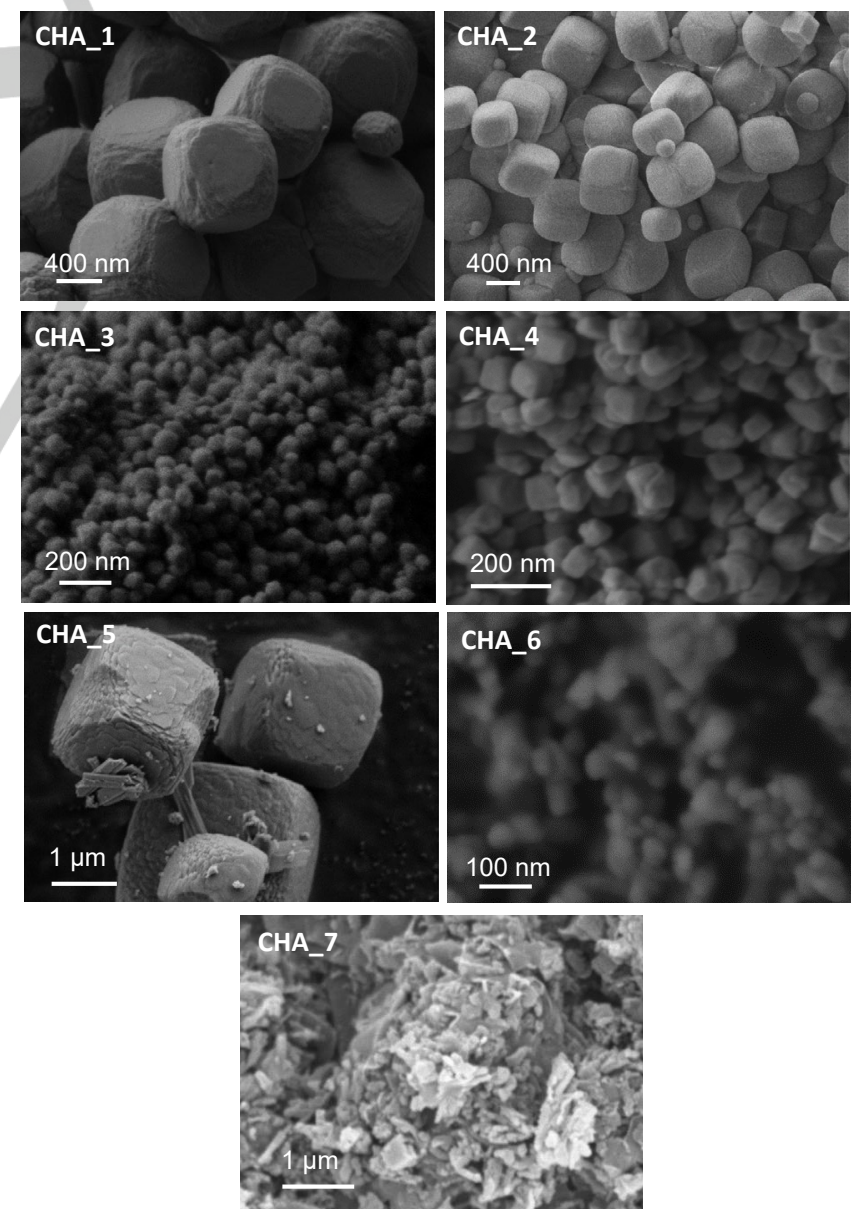

Figure 2. SEM images of the synthesized CHA-related materials. 
However, as far as we know, the synthesis of the Na-free nanosized SSZ-13 materials has not been described in the literature. To attempt their preparation, we proposed the use of pre-crystallized high-silica FAU-type zeolites as the sole source of $\mathrm{Si}$ and $\mathrm{Al}$ in the synthesis media, since recently a few nanocrystalline zeolites have been achieved following this approach. ${ }^{[11]}$ According to this, the Na-free synthesis of the nanocrystalline SSZ-13 zeolites has been carried out by combining the use of FAU and TMAda as $\mathrm{Si}$ and Al source and OSDA, respectively. For this purpose, two commercially available FAU zeolites (CBV720, Si/Al 14; CBV760, Si/Al 26) have been employed as sole $\mathrm{Si}$ and $\mathrm{Al}$ precursors for the synthesis of $\mathrm{CHA}$ 3 and $\mathrm{CHA}-4$, respectively (see $\mathrm{SI}$ for synthesis details). The resultant solids show the characteristic PXRD patterns of the $\mathrm{CHA}$ structure (see CHA-3 and CHA-4 in Figure S1). Very interestingly, the achieved crystals of $\mathrm{CHA}-3$ and $\mathrm{CHA}-4$ show homogeneous nanocrystallites for both samples, with average sizes of 60 and $80 \mathrm{~nm}$, respectively (see FE-SEM images in Figure 2). The chemical analyses reveal final Si/Al molar ratios of 14.2 and 24.1 for the CHA-3 and CHA-4 samples (see Table 2), which are similar values to those initially introduced in the synthesis gels by the FAU-type precursors.
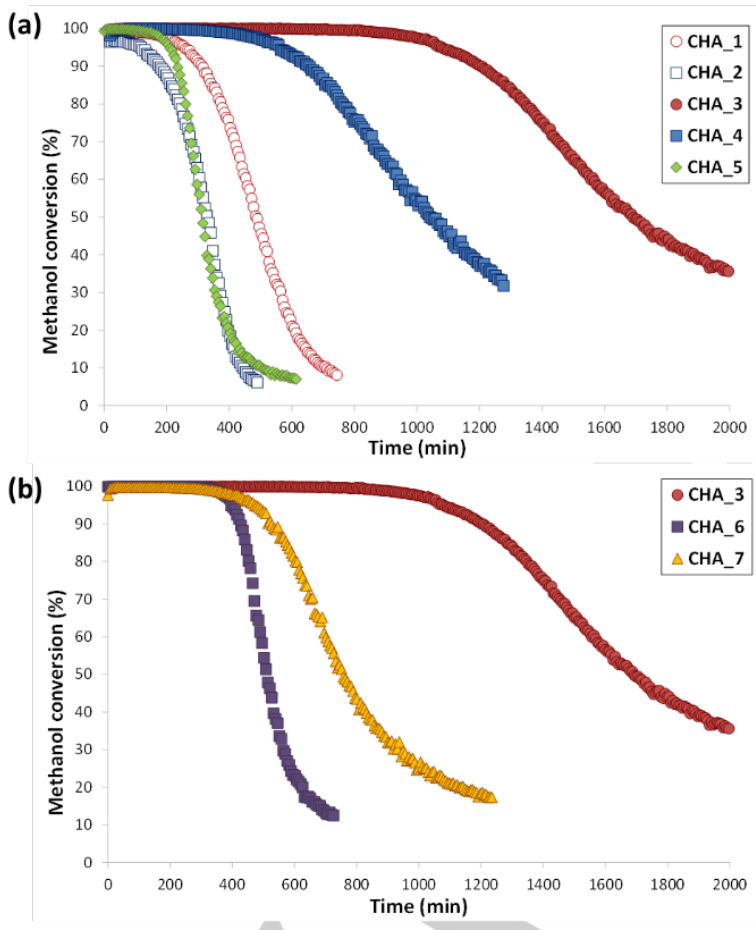

Figure 3. Methanol conversion profiles for the Na-free CHA-related materials compared with standard $\mathrm{CHA}(\mathrm{A})$, and different nanocrystalline CHA-related materials (B). The reaction conditions were: $T=350^{\circ} \mathrm{C}, 30 \mathrm{ml} / \mathrm{min}$ of $\mathrm{N}_{2}$ bubbled at $-17^{\circ} \mathrm{C}, \mathrm{WHSV}=0.8 \mathrm{~h}^{-1}, \mathrm{~W}_{\text {cat }}=50 \mathrm{mg}$

The Na-free micron- and nano-sized materials have been calcined at $580^{\circ} \mathrm{C}$ to remove the organic species occluded within the crystalline structures, and the coordination of the Al atoms in these calcined materials has been studied by solid ${ }^{27} \mathrm{AI}$ MAS NMR spectroscopy (see Figure S2). The solid ${ }^{27}$ AI MAS NMR spectra of the three SSZ-13 zeolites are similar, presenting a main band centered at $\sim 55 \mathrm{ppm}$ assigned to tetrahedrally coordinated $\mathrm{Al}$ atoms in framework positions, and a very small signal at $\sim 0 \mathrm{ppm}$ assigned to octahedrally coordinated Al species in extraframework positions. A careful quantification indicates that above $90-95 \%$ of the entire Al species remain in framework positions in the Na-free micron- and nano-sized SSZ-13 materials.

These Na-free SSZ-13 catalysts have been tested for the MTO reaction at $\mathrm{WHSV}=0.8 \mathrm{~h}^{-1}$ and $350^{\circ} \mathrm{C}$ (see reaction conditions in the $\mathrm{SI}$ ). As it can be clearly seen in Figure $3 \mathrm{a}$, the nano-sized Na-free SSZ-13 materials, CHA_3 (Si/AI 15) and CHA_4 (Si/Al 25), present a remarkably increase of their catalyst lifetimes compared to their micron-sized counterparts, CHA_1 (Si/Al 15) and CHA_2 (Si/Al 25), with analogous Si/Al molar ratios. For both studied $\mathrm{Si} / \mathrm{Al}$ molar ratios, it can be observed a 4-5-fold increase of the catalyst lifetime by reducing the crystal from the micron- to the nano-size (CHA_3/CHA_1 4.2 and CHA 4/CHA_2 4.8, considering the methanol conversion drops below 95\%, see Table 2).

The worst catalytic behavior of the Na-free SSZ-13 materials synthesized with a Si/Al molar ratio of 25 compared to those prepared with $\mathrm{Si} / \mathrm{Al}$ molar ratios of 15 could be explained by the lower amount of Al-containing $\mathrm{CHA}$-cavities within the former materials and, consequently, in the reactor. In order to validate this hypothesis, an additional experiment maintaining constant the $\mathrm{Al}$ content in the reactor for the two Na-free nanosized materials has been carried out. In this sense, the MTO catalytic activity of $83 \mathrm{mg}$ of the $\mathrm{CHA}-4$ sample $(\mathrm{Si} / \mathrm{Al}=25)$ has been evaluated and compared with $50 \mathrm{mg}$ of $\mathrm{Na}$-free nanosized $\mathrm{CHA}$ 3 sample $(\mathrm{Si} / \mathrm{Al}=15)$. As seen in Figure $\mathrm{S} 10$, both materials perform virtually identical when the Al content is analogous in the reactor.

Table 3. Catalytic properties for the different CHA-based zeolites for MTO reaction (reaction conditions: $\mathrm{T}=350^{\circ} \mathrm{C}, \mathrm{WHSV}=0.8 \mathrm{~h}^{-1}, \mathrm{~W}_{\mathrm{cat}}=50 \mathrm{mg}$ ).

\begin{tabular}{|c|c|c|c|c|c|}
\hline \multirow[b]{2}{*}{ Sample } & \multicolumn{2}{|c|}{ Catalyst lifetime (min) } & \multicolumn{3}{|c|}{ Selectivity (\%) at $\mathrm{X}_{95}$} \\
\hline & $\mathrm{X}_{95^{[\mathrm{a}]}}$ & $X_{50}^{[b]}$ & $\mathrm{C}_{2}=$ & $\mathrm{C}_{3}=$ & $\mathrm{C}_{4}=$ \\
\hline CHA_1 & 260 & 490 & 45.1 & 37.0 & 12.4 \\
\hline CHA_2 & 117 & 335 & 44.1 & 36.6 & 13.0 \\
\hline CHA_3 & 1085 & 1693 & 47.1 & 34.2 & 12.1 \\
\hline CHA_4 & 564 & 1048 & 46.8 & 35.1 & 12.3 \\
\hline CHA_5 & 210 & 316 & 39.3 & 37.8 & 15.4 \\
\hline CHA_6 & 397 & 514 & 42.3 & 40.6 & 11.9 \\
\hline CHA_7 & 472 & 757 & 43.2 & 37.4 & 14.2 \\
\hline
\end{tabular}

At this point, the synthesis of Na-containing micron- and nanosized SSZ-13 materials is proposed to evaluate the influence of sodium in the synthesis media on the MTO catalytic activity. On the one hand, the standard synthesis of the SSZ-13 zeolite reported by Zones has been prepared as the micron-sized Nacontaining SSZ-13 material. ${ }^{[12]}$ Its synthesis recipe requires amorphous sources of $\mathrm{Si}$ and $\mathrm{Al}$, and the combination of TMAda ${ }^{+}$ and $\mathrm{Na}^{+}$cations (see CHA_5 in Table 1 and synthesis details in 
the SI). The resultant solid shows the PXRD pattern of the crystalline CHA phase (see Figure S1), and an average crystal size of 1-1.5 $\mu \mathrm{m}$ with a Si/Al molar ratio of $\sim 15$ (see CHA_5 in Table 2).

On the other hand, two different synthesis of Na-containing nano-sized $\mathrm{CHA}$ materials reported in the literature have been prepared, a surfactant-modified SSZ-13 ${ }^{[9 \mathrm{c}]}$ and the SSZ-62 zeolite. ${ }^{[8]}$ The synthesis gels of these two materials require $\mathrm{Si} / \mathrm{Al}$ molar ratios close to $\sim 15$, the presence of sodium hydroxide, and the use of TMAda ${ }^{+}$as OSDA (see Table 1 and experimental details in the $\mathrm{SI}$ ). First, the surfactant-modified nanosized $\mathrm{Na}$ SSZ-13 involves the introduction of cetyltrimethylammonium (CTMA) in the synthesis media after a previous ageing treatment, to prevent the excessive crystal growth. ${ }^{[9 c]}$ The achieved material shows small and plane-based CHA crystallites, with crystal sizes ranging from 50 to $150 \mathrm{~nm}$ (see CHA_7 in Figure 2), and a large external surface area $\left(\sim 130 \mathrm{~m}^{2} / \mathrm{g}\right.$, see CHA_7 in Table 2). The chemical analysis reveals a Si/Al molar ratio of $\sim 17$ (see CHA_7 in Table 2), similar to the theoretical ratio introduced initially in the synthesis gel. Second, and according to the methodology described by Zones et al., ${ }^{[8]}$ the preparation of the SSZ-62 material is favored under highly alkaline synthesis conditions, requiring higher sodium hydroxide contents $\left(\mathrm{NaOH} / \mathrm{SiO}_{2} \sim 0.4\right.$, see Table 1 and experimental details in the $\mathrm{SI}$ ). The PXRD pattern reveals the crystallization of the CHA material (see CHA_6 in Figure $\mathrm{S} 1$ ), while the study of the sample by FE-SEM shows the extraordinary nanocrystalline nature of the sample $(\sim 30 \mathrm{~nm}$, see CHA_6 in Figure 2). The chemical analysis indicates that the Si/Al molar ratio of the nanosized $\mathrm{CHA}_{-} 7$ material is $\sim 8.5$, which is relatively lower than the theoretical $\mathrm{Si} / \mathrm{Al}$ molar ratio introduced initially in the synthesis gel (Si/Al 15). This fact could be explained by the high alkalinity required for the synthesis of the SSZ-62, forcing to some silicon species to remain as soluble silicates. The results are in line with those obtained by Zones et al. ${ }^{[8 a]}$

The as-prepared Na-containing micron- and nano-sized SSZ13 materials have been calcined at $580^{\circ} \mathrm{C}$ and $\mathrm{NH}_{4}$-exchanged to generate the acid-form. These calcined samples have been evaluated by ${ }^{27} \mathrm{Al}$ MAS NMR spectroscopy to study the coordination of the Al atoms. In all cases, the solid ${ }^{27} \mathrm{Al}$ MAS NMR spectra indicate that almost $90-95 \%$ of the Al species remain in tetrahedral coordination, as revealed by the main band centered at $~ 55$ ppm (see CHA_5, CHA_6 and CHA_7 in Figure S2).

When the micron-sized CHA-5 material has been tested for the MTO reaction, methanol conversion drops below $95 \%$ and $50 \%$ after 210 and 316 minutes have been observed (see Figure $3 \mathrm{a}$ and Table 2). These values are lower than those obtained with the Na-free micron-sized CHA_1 catalyst (260 and 490 minutes to achieve $X_{95}$ and $X_{50}$, see Table 3). Since both materials have similar crystal sizes and Si/Al molar ratios (see Table 2), it could be hypothesized that the presence of $\mathrm{Na}^{+}$during the preparation of the standard CHA_5 zeolite has indeed an influence on the Al distribution within the crystals. In addition, the micron-sized CHA_2 sample, which was synthesized under Na-free conditions with a Si/Al molar ratio of $\sim 26$, performs with a similar methanol conversion profile compared to the standard CHA_5 zeolite ( $\mathrm{X}_{50}$ 320-335 minutes, see Table 3), even when the standard SSZ13 presents a remarkably lower Si/Al molar ratio $(\sim 15$, see Table 2). This result would also confirm the negative effects of sodium in the synthesis media for homogenously distributing the aluminum atoms as single $\mathrm{Al}$ per $\mathrm{CHA}$ cavities, and its direct implications on the MTO catalytic performance.

The two nano-sized CHA materials synthesized in presence of $\mathrm{Na}$ show a clear enhancement of the catalyst lifetime (X50 514 and 757 for the CHA_6 and CHA_7, respectively, see Figure $3 \mathrm{~b}$ and Table 3), compared to the standard micron-sized CHA_5, which was also synthesized with $\mathrm{Na}\left(\mathrm{X}_{50} \sim 316\right.$ minutes, see Table 3). However, the Na-free nanocrystalline CHA_3 sample performs much better than the nanosized $\overline{\mathrm{CHA}}$ zeolites synthesized in presence of sodium cations, presenting a 3-and 2.5-fold increase compared to CHA_6 and CHA_7, even when the crystal sizes of these materials are analogous or remarkably smaller (see Figure 2).

To understand the influence of sodium on the Al distribution in SSZ-13 zeolite, the stability of different structures containing $\mathrm{TMAda}^{+}, \mathrm{Na}^{+}$, or a combination of both as compensating cations, was studied by means of DFT calculations. TMAda ${ }^{+}$cations always occupy the center of the large $\mathrm{CHA}$ cavities and preferentially stabilize the Al atoms located close to the methyl groups directly bonded to the $\mathrm{N}$ atom (see Figure S11a), while $\mathrm{Na}^{+}$cations are usually placed in the center of the 6-rings of the small cages, forming strong bonds with the framework oxygen atoms (see Figure S11b). Al pairs, defined as Al atoms in close proximity separated by either one or two $\mathrm{Si}$ atoms $\left[\mathrm{Al}-\mathrm{O}(-\mathrm{Si}-\mathrm{O})_{\mathrm{x}}-\mathrm{Al} ; \mathrm{x}=1,2\right]$, require the presence of two proximal compensating cations. Two TMAda ${ }^{+}$cannot be placed in one cavity and have to be necessarily placed in two different cavities. Therefore, only some particular arrangements of pairs could be stabilized by these cations. Structures with two Al atoms in the same 6-ring are $>5 \mathrm{kcal} / \mathrm{mol}$ less stable than distributions with the two Al in different cavities, and Al pairs with only one Si between the two Al atoms are clearly unstable (see Figure S11C). However, the location of $\mathrm{Na}^{+}$in the center of the 6 -ring permits the presence of a TMAda ${ }^{+}$cation in close proximity (see Figure S11d), allowing the stabilization of structures containing two $\mathrm{Al}$ atoms in the same small cage, or in the same 6-ring.

With these trends in mind, we explored a number of $\mathrm{Al}$ distributions corresponding to a Si/Al = 11 (three $\mathrm{Al}$ per unit cell) using either TMAda ${ }^{+}$or a combination of $\mathrm{TMAda}^{+}$and $\mathrm{Na}^{+}$as compensating cations. As clearly observed in Table S1, the most stable structures using exclusively $\mathrm{TMAda}^{+}$as compensating cations are those containing just one $\mathrm{Al}$ atom per cavity (structures 1-5, see Figure S2), with only one Al-pair containing distribution (structure 6 ) being stabilized by a TMAda ${ }^{+}$cation placed in the neighboring cavity. The rest of distributions are significantly less stable. In contrast, when one of the three framework $\mathrm{Al}$ atoms is compensated by a $\mathrm{Na}^{+}$cation placed in the center of the 6-ring, most distributions containing Al pairs are stabilized. Structure 6 becomes the global minimum, and some other systems with Al pairs (like structures 10 and 11) compete in stability with the highly dispersed systems (structures 1-3, see Figure S2) obtained in the absence of $\mathrm{Na}^{+}$. It can then be concluded from the DFT study that, from a thermodynamic point of view, the presence of $\mathrm{Na}^{+}$together with TMAda+ leads to an increase in the concentration of Al pairs in the CHA structure. This conclusion highly supports the observation made by Gounder et al. in the sense that the number of $\mathrm{Al}$ pairs increase when 
increasing $\mathrm{Na}^{+}$content in the zeolite for a given Si/Al molar ratio. ${ }^{[10 a]}$

The results presented here not only highlight the importance of controlling the crystal size in the nanometric scale of the CHAbased zeolite to improve the diffusion rate of reactants and products, but also put in relevance the tremendous impact of the synthesis methodology employed in its preparation on the final catalytic properties. Indeed, it has been shown that the Si/AI molar ratio in the final solid can influence the catalytic activity of the CHA-related materials for the MTO, together with the $\mathrm{Al}$ distribution within the CHA cavities for given Si/Al molar ratios. Considering that the theoretical Si/Al molar ratio to ideally obtain one Al per $\mathrm{CHA}$ cavity is 11 , the preparation of a nanosized $\mathrm{CHA}$ zeolite with a lower $\mathrm{Si} / \mathrm{Al}$ ratio would necessarily result in a material containing more than one Al per cavity, which would accelerate the undesired olefin oligomerization and condensation reactions leading to coke formation and catalyst deactivation, as it occurs for instance for the SSZ-62 catalyst (see CHA_6 in Figure $3 b$ ). Moreover, it could also be speculated that the formation of bulky aromatic hydrocarbon pool intermediates in all (or most) of the $\mathrm{CHA}$ cavities, would result in more diffusional problems for reactant and products, enforcing the catalyst deactivation by coke formation. Thus, it seems that intermediate Si/Al molar ratios (i.e. 15 ) would prevent both the diffusional problems offered by the excessive hydrocarbon pool formation within $\mathrm{CHA}$ crystals with relatively low Si/Al molar ratios (i.e. 8), and the moderately catalyst deactivation when only few $\mathrm{CHA}$ cavities are able to induce the hydrocarbon pool formation in zeolites with high Si/Al molar ratios (i.e. 25).

The results obtained can also have significant practical implications since it would allow the use of smaller amount of zeolite in the industrial catalyst with important implications in cost and mechanical resistance, or can allow achieving a higher throughput in the process.

\section{Experimental Section}

Experimental details for zeolite syntheses, characterization techniques, catalytic evaluation for the MTO reaction, and computational data, are extensively described in the Supporting Information.

\section{Acknowledgements}

This work has been supported by the EU through ERC-AdG2014-671093, by the Spanish Government-MINECO through "Severo Ochoa" (SEV-2016-0683) and MAT2015-71261-R, and by the Fundación Ramón Areces through a research contract of the "Life and Materials Science" program. E.M.G. acknowledges "La Caixa-Severo Ochoa" International PhD Fellowships (call 2015), C.L. acknowledges China Scholarship Council (CSC) for a Ph.D fellowship, and N.M. thanks MINECO for a pre-doctoral fellowship (BES-2013-064347). Red Española de Supercomputación (RES) and Centre de Càlcul de la Universitat de València are gratefully acknowledged for computational resources.
Keywords: Methanol-to-olefins • small pore zeolite $•$ chabazite • Al pairs $•$ light olefins

[1] P. Tian, Y. Wei, M. Ye, Z Liu, ACS Catal 2015, 5, 1922-1938.

[2] (a) U. Olsbye, S. Svelle, M. Bjørgen, P. Beato, T. V. W. Janssens, F. Joensen, S. Bordiga, K. P. Lillerud, Angew. Chem., Int. Ed. 2012, 51 5810-5831; (b) M. Moliner, C. Martínez, A. Corma, Chem. Mater. 2014, 26, 246-258.

[3] M. Stöcker, Micropor. Mesopor. Mater. 1999, 29, 3-48.

[4] (a) S. Wilson, P. Barger, Micropor. Mesopor. Mater. 1999, 29, 117126; (b) K. Hemelsoet, J. Van der Mynsbrugge, K. De Wispelaere, M. Waroquier, V. S. V., ChemPhysChem 2013, 14, 1526-1545.

[5] (a) J. F. Haw, D. M. Marcus, Top. Catal. 2005, 34, 41-48; (b) F. Bleken M. Bjørgen, L. Palumbo, S. Bordiga, S. Svelle, K. P. Lillerud, U. Olsbye, Top. Catal. 2009, 52, 218-228.

[6] B. M. Lok, C. A. Messina, R. L. Patton, R. T. Gajek, T. R. Cannan, E. M. Flanigen, J. Am. Chem. Soc. 1984, 106, 6092-6093.

[7] J. Q. Chen, A. Bozzano, B. Glover, T. Fuglerud, S. Kvisle, Catal. Today 2005, 106, 103-107.

[8] (a) S. I. Zones, L. T. Yuen, S. J. Miller, WO/2003/020641 2003; (b) T. Takata, N. Tsunoji, Y. Takamitsu, M. Sadakane, T. Sano, Microp. Mesop. Mater. 2016, 225, 524-533.

[9] (a) L. Wu, V. Degirmenci, P. C. M. M. Magusin, B. M. Szyja, E. J. M Hensen, Chem. Commun. 2012, 48, 9492-9494; (b) L. Wu, V Degirmenci, P. C. M. M. Magusin, N. J. H. G. M. Lousberg, E. J. M. Hensen, J. Catal. 2013, 298, 27-40; (c) Z. Li, M. T. Navarro, J. Martinez-Triguero, J. Yu, A. Corma, Catal. Sci. Technol. 2016, 6 58565863; (d) X. Zhu, N. Kosinov, J. P. Hofmann, B. Mezari, Q. Qian, R. Rohling, B. M. Weckhuysen, J. Ruiz-Martínez, E. J. M. Hensen, Chem Commun. 2016, 52, 3227-3230.

[10] (a) J. R. Di lorio, R. Gounder, Chem. Mater 2016, 28, 2236-2247; (b) J. R. Di lorio, C. T. Nimlos, R. Gounder, ACS Catal. 2017, 7, 6663 6674 .

[11] (a) D. Xie, S. I. Zones, R. J. Saxton, WO2016/032565 2016; (b) N Martin, Z. Li, J. Martinez-Triguero, J. Yu, M. Moliner, A. Corma, Chem. Commun. 2016, 52, 6072-6075.

[12] S. I. Zones, US4544538 1985. 


\section{Entry for the Table of Contents}

\section{COMMUNICATION}

The control of the Al distribution and the crystal size in the CHA-type catalyst results in a 5-fold increase of the catalyst life for the MTO reaction compared to standard CHA-based catalysts. The optimized aluminum distribution together with the small crystallites maximize the formation of the MTO hydrocarbon pool intermediates, while improve diffusion pathways.
Nanosized CHA ( $<100 \mathrm{~nm}$ ) for MTO

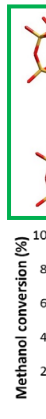

Eva M. Gallego, Chengeng Li, Cecilia Paris, Nuria Martín, Joaquín MartínezTriguero, Mercedes Boronat, Manuel Moliner, ${ }^{*}$ Avelino Corma ${ }^{*}$

Page No. - Page No.

Making nanosized CHA zeolite with controlled Al distribution for optimizing MTO performance 